\title{
GEOGRAFIA E EDUCAÇÃO AMBIENTAL NA PERSPECTIVA DOS MAPAS MENTAIS EM DIFERENTES CONTEXTOS ESCOLARES DE AQUIDAUANA (MS)
}

\author{
Larissa Cristina Brandão Cardoso ${ }^{1}$ \\ Eva Teixeira dos Santos ${ }^{2}$
}

Resumo: A alfabetização em geografia e ambiental tem potencial de se efetivar na prática do ser, ultrapassando o ensino mecânico descontextualizado do cotidiano e espaço vivido. Assim, pensa-se a ambas as perspectivas no contexto escolar dialogando com a prática social do estudante e também do professor. $O$ ensino não deve ser alheio à realidade, ao que é vivido pelo estudante em seu espaço, o "chão", por meio do cotidiano. Esta pesquisa visou conhecer e analisar o ensino de geografia e educação ambiental em três contextos escolares em Aquidauana, e ideou o espaço enquanto uma produção da sociedade, no qual influencia cada ser na sua relação e percepção espacial e ambiental, configurando uma relação coexistente. Assim, as 'leituras de mundo' que procedem do cotidiano no espaço vivido, o 'chão', configuram uma geografia viva que produz percepções possibilitadas a ser sistematizadas pelos componentes da educação básica em foco nesta pesquisa, como a escola indígena, a citadina e a pantaneira. A pesquisa foi realizada a partir de levantamentos documentais, bibliográficos e trabalhos de campo. A diversidade dos estudantes se destacou e potencializou a análise dialética das leituras de mundo, enquanto uma construção social. Os cotidianos escolares, dos estudantes e dos professores não são estáticos, pois se tratam do dinamismo do devir do 'chão' de todos estes envolvidos. A compreensão espacial e ambiental pode estar para os estudantes com significação a pensar o cotidiano e ser no espaço vivido, e não limitados com conceitos estáticos.

Palavras-chave: Espaço Vivido; Meio Ambiente; Representação.

\footnotetext{
${ }^{1}$ Instituto Federal de Mato Grosso do Sul. E-mail: larissa.cardoso@ifms.edu.br

2 Universidade Federal de Mato Grosso do Sul. E-mail: evasantos.ufms@gmail.com
}

Revbea, São Paulo, V. 12, № 2: 355-373, 2017.

revista brasileira educação ambiental 


\title{
Geografia, "chão" e educação ambiental
}

\author{
O que se entende por Geografia? É o \\ estudo, que estuda esse tipo de matéria \\ estuda a vida Sabe melhor É sempre \\ Bom, saber um pouco mais Afinal. \\ Ninguém sabe de tudo (15 anos, 9ํㅡ).
}

Para o estudante, a Geografia ensinada no nível básico "estuda a vida", ou seja, o ensino de Geografia corresponde às perspectivas da Geografia enquanto ciência. Para este momento, importa entender a que perspectiva da Geografia o trabalho enfoca, para assim entender conceitos, concepção de ensino de Geografia e, mais a frente, percepção de Geografia a partir de mapas mentais.

Para toda a ciência, para todo saber deve ser colocada a questão das premissas epistemológicas; o processo científico está ligado à uma história e deve ser encarado, de um lado, nas suas relações com as ideologias, de outro, como prática ou como poder (LACOSTE, 1988, p.22).

Lacoste enfatiza a importância do conhecimento epistemológico da ciência estudada, pois o decorrer de cada ciência tem ligação com um contexto histórico, respondendo as premissas ideológicas.

Estudara nos livros demais. Porém aprendia melhor no ver, no ouvir, no pegar, no provar e no cheirar (BARROS, 2006, p. 40).

O contexto do poema narra que Sócrates viveu alfabetizando-se culturalmente, conhecendo a si mesmo, mas que, no final da vida, percebeu que de nada sabia e aprendia mais por meio da cinestesia. A conjectura da obra de "Memória inventada" de Barros corrobora com a perspectiva de alfabetização geográfica desta pesquisa, ou seja, de aprender a partir das experiências com o espaço vivido do cotidiano, chão, com as "leituras de mundo" (FREIRE, 2006, p.19). Isso é importante, pois "se o espaço não é encarado como algo em que o homem (o aluno) está inserido, natureza que ele próprio ajuda a moldar, a verdade geográfica do indivíduo se perde e a Geografia torna-se alheia para ele" (RESENDE, 1986, p.19-20). O ensino precisa ser significativo para o estudante, e, no panorama geográfico remetido aqui, fundado na percepção de que o próprio faz parte do processo de produção e relação espacial, a partir das suas leituras de mundo, chegando à alfabetização. 
Retomando a discussão do "chão", esse consiste no espaço vivido por meio do cotidiano de cada ser que forma a sua "leitura de mundo", que é um entendimento não sistematizado, antecedente da leitura da palavra escrita. Freire viveu essa perspectiva, pois a sua alfabetização da leitura da palavra não foi a partir do "ba-be-bi-bo-bu", mas da vivência no "chão" da sua infância: "Fui alfabetizado no chão do quintal de minha casa, à sombra das mangueiras, com palavras do meu mundo e não do mundo maior dos meus pais. O 'chão' foi o meu quadro-negro; gravetos, o meu giz” (FREIRE, 2006, p.15). A leitura da palavra partiu do conhecimento do seu quintal, da sombra das mangueiras e do "chão", ou seja, intermediou o espaço vivido à sua alfabetização.

A Política Nacional de Educação Ambiental, Lei no 9.795, de 27 de Abril de 1999, regula a Educação Ambiental (EA), que, conforme o caput do Art. 1ํ, é a criação, por uma pessoa ou um grupo, de "valores sociais, conhecimentos, habilidades, atitudes e competências" preocupando-se com a "conservação" e "sustentabilidade" do meio ambiente. Interessado nisso, Art. $2^{\circ}$ menciona que ela deve estar inserida "na educação nacional" em todos os níveis e modalidades da mesma, e a escola, enquanto "instituição educativa", consiste numa das instâncias incumbidas para essa demanda educacional, conforme o inciso II do Art. 3ํㅡ (BRASIL, 1999).

Para Segura (2001, p.21), a escola caracteriza uma das primeiras instâncias que adotou a temática ambiental. Essa inserção resulta da exigência prevista nos Parâmetros Curriculares Nacionais (PCN's), pois, de acordo com este documento, o Meio Ambiente como Tema Transversal precisa ser inserido nos currículos escolares. Segundo esse documento oficial, "é fundamental, na sua abordagem, considerar os aspectos físicos e biológicos e, principalmente, os modos de interação do ser humano com a natureza, por meio de suas relações sociais, do trabalho, da ciência, da arte e da tecnologia" (BRASIL, 2014, p.169, grifos da pesquisadora).

A discussão ambiental pode ser conceituada pelo que é exigido oficialmente, pois:

A Educação Ambiental é a incorporação de critérios socioambientais, ecológicos, éticos e estéticos, nos objetivos didáticos da educação. Pretende construir novas formas de pensar incluindo a compreensão da complexidade e das emergências e inter-relações entre os diversos subsistemas que compõem a realidade (MEDINA; SANTOS, 2003, p.25).

Segundo esse entendimento, a EA corresponde a uma perspectiva de discutir a relação socioambiental de forma didática para que possibilite que 0 cidadão/ser/estudante pense a realidade e construa os seus valores a partir do cuidado com o meio ambiente. No entanto, a EA: 
[...] situa-se mais em areias movediças do que em litorais ensolarados. Mas, por isso mesmo, a Educação Ambiental pode ser uma preciosa oportunidade na construção de novas formas de ser, pensar e conhecer que constituem um novo campo de possibilidades de saber (SATO; CARVALHO, 2005, p. 12).

Refletindo acerca da EA, suas respostas, seus resultados e sua contribuição, conforme o que está posto oficialmente, esta pesquisa indagou como a abordagem da EA nas aulas de Geografia contribui para o aprendizado do estudante. Tendo em vista que, se esse entendimento é construído de forma mecânica e alheia ao cotidiano ambiental e espacial do estudante, não alcança ao próprio objetivo dos documentos oficiais.

Há de se lembrar que o contexto histórico da relação do homem com a natureza explica o porquê de a abordagem ambiental ser mecânica e possuir um discurso culposo que nada contribui para os próprios objetivos da EA, que pode não alcançar a realidade do ser ou da comunidade, considerando que:

Nós não encontramos problemas ou questões a serem estudados e explicados cientificamente fora de nós mesmos num mundo independente. [...] Então, a ciência, como um domínio cognitivo, existe e se desenvolve como tem sempre expressando os interesses, desejos, ambições, aspirações e fantasias dos cientistas, apesar de suas alegações de objetividade e independência emocional (MATURANA, 2006, p. 147 apud GONZALEZ, 2013, p. 47-48).

A vivência no espaço a partir do cotidiano deve estar intrinsecamente interligada com a abordagem ambiental na educação, pois existe "[...] saberes/fazeres socioambientais das práticas [...], inventados nos devires cotidianos, constituindo o que denominamos de Educações Ambientais Autopoiéticas, preenchidas por afetos, conflitos, estratégicas, astúcias [...]" (GONZALEZ, 2013, p.72). Assim como Gonzalez, esta pesquisa possibilitou à pesquisadora repensar a EA que deve estar no cotidiano, e partir da sala de aula para a realidade, o espaço, o cotidiano e o grupo de sociedade em que 0 estudante está inserido.

Nesta pesquisa, acredita-se que o entendimento dicotômico entre homem e natureza corrobora com o rompimento da autopoiese e com o ideário de competição. $O$ que nos constrói enquanto ser vivo, seja a relação com o espaço ou com os outros seres, não está inserido no pensar de toda a dimensão ambiental, pois, ao considerar que a natureza deve servir ao homem e que esse próprio não está inserido na natureza, ou seja, ele não é considerado natureza, demonstra-se e se reafirma, por meio do processo 
histórico, o quanto a ciência está intrinsecamente interligada às percepções pessoais, à autopoiese de cada ser.

Pensar nos problemas ambientais alheios aos problemas humanos consiste em descaracterizar o sentido que é ser natureza versus ser homem, de forma hierarquizada. $\mathrm{E}$ isto parte da compreensão do ser acerca de si mesmo, visto que:

Tuan declara sua intenção de contribuir para a compreensão de nós mesmos, pois acredita que sem a auto compreensão não seja possível esperar por soluções duradouras para os problemas ambientais que, fundamentalmente, são problemas humanos e, por sua vez, todos os problemas humanos "dependem do centro psicológico da motivação, dos valores e atitudes que dirigem as energias para os objetivos" (TUAN, 1980 apud VIEIRA, VARGAS, ZANON, 2015, p. 2).

Nessa perspectiva, é o psicológico do ser que constituirá no conjunto de práticas acerca dos problemas ambientais e sua possível reparação/solução.

\section{Caminho metodológico}

Conforme apresentado na Figura 1, a pesquisa foi desenvolvida em três contextos escolares. A Escola Municipal Indígena Marcolino Lili (EI), localizada na aldeia Lagoinha, a cinquenta e oito quilômetros da unidade dois da Universidade Federal de Mato Grosso do Sul (UFMS), em Aquidauana; os mapas mentais apresentam características da El a partir das percepções dos estudantes dessa escola, com ícones que indicam o que realmente existe no entorno da escola, como o formato de sua construção e sua localização, frente às outras construções em seu entorno. Outra explicação para a escolha da El consiste na perspectiva quantitativa que reafirma o foco da educação indígena, pois o município possui o segundo maior contingente indígena do estado (MARQUES; SOUZA, p.1), e que o Estado de Mato Grosso do Sul está na segunda colocação no que ao tamanho da população indígena no país. A Escola Municipal Erso Gomes (EC), localizada nas proximidades da unidade dois da UFMS, sendo perceptível, que a localização contextualizada por mapas mentais dos estudantes dessa escola demonstram elementos que existem na cidade, como categorizado ao modo de vida urbano, citado por um desenho como "zona urbana", havendo menção também ao costume de uso de celular nesse cotidiano. A Escola Municipal Polo Pantaneira Núcleo Joaquim Alves Ribeiro (EP), localizada na Fazenda Taboco que dista cinquenta quilômetros da unidade dois da UFMS, cujos signos que representam a EP fazem menção ao rio, barcos, animal, e, além disto, foi representada a composição da Rodovia 419, que dá acesso à Fazenda Taboco.

O mapa de localização formal foi acrescido dos mapas mentais para dar mais sentido, pois, para Richter (2011, p.125), "os mapas mentais possibilitam a seu autor incluir elementos subjetivos que, na maioria das vezes, não estão

revista brasileira educação ambiental 
presentes nos mapas tradicionais", o que pode ser percebido pelos ícones desenhados pelos estudantes com detalhes, representando a realidade dos espaços.
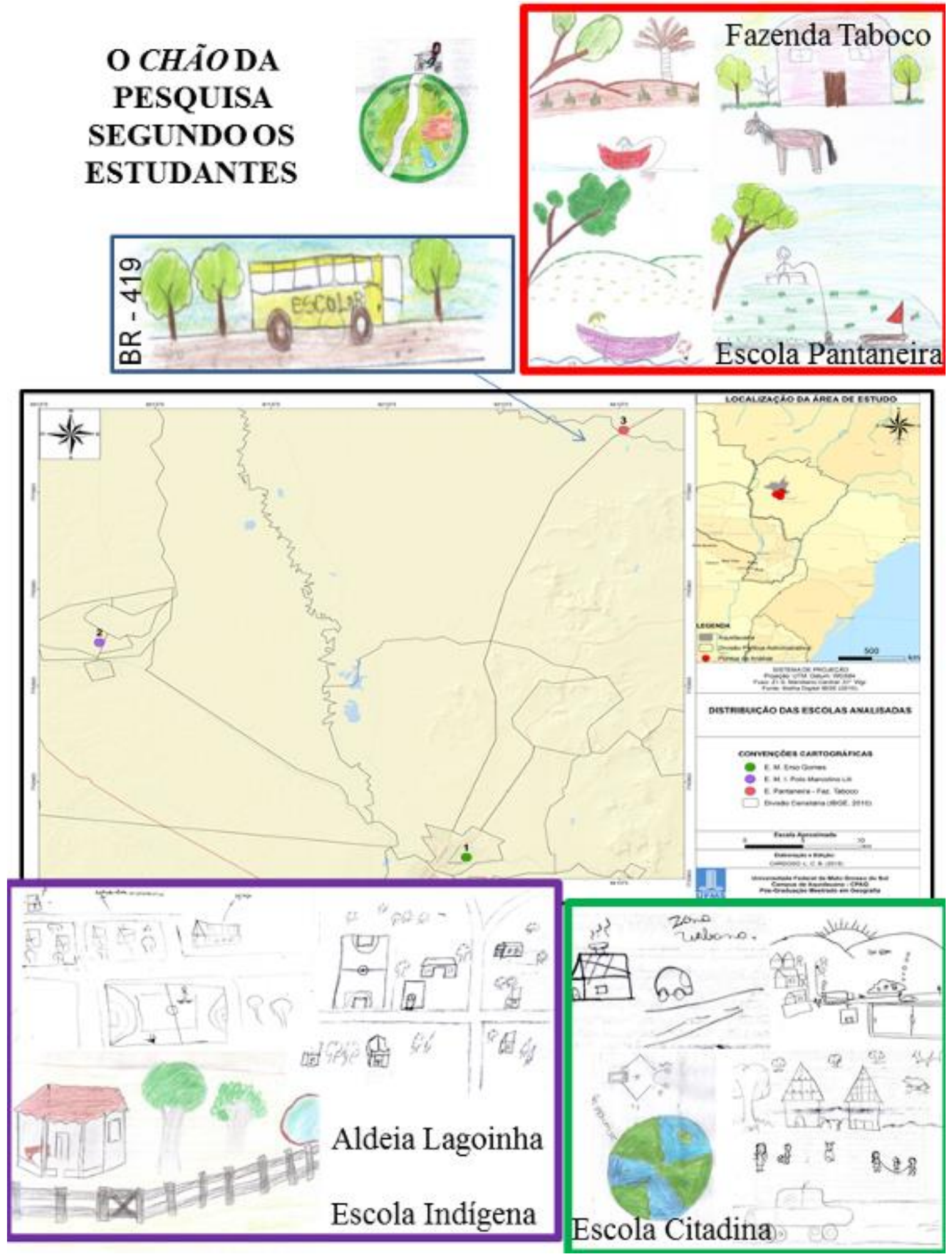

Figura 1: Localização das escolas estudadas. 
Acerca dos procedimentos metodológicos, foram desenvolvidos em três momentos, com a pesquisa documental, bibliográfica e de campo, sendo que a pesquisa aconteceu nos anos de 2014 e 2015.

A aplicação dos mapas mentais e das narrativas aconteceu em todas as turmas dos anos finais do ensino fundamental da El e EP (6은 $7^{\circ}, 8^{\circ}$ e $\left.9^{\circ}\right)$. $\mathrm{Na}$ $\mathrm{EC}$, foram aplicados em quatro turmas dos anos finais do fundamental ( $8^{\circ} \mathrm{A}$, $8^{\circ} \mathrm{B}, 9^{\circ} \mathrm{A}$ e $\left.9^{\circ} \mathrm{B}\right)$. Os desenhos são expressivos com relação aos contextos espaciais vivenciados pelos estudantes, além das atividades cotidianas. Acredita-se que com essas atividades têm-se informação da origem dos estudantes e seus entendimentos para o meio ambiente.

Os estudantes desenharam nos mapas mentais suas percepções de EA, a partir da sua vivência espacial, e escreveram narrativas autobiográficas. Os mapas mentais enquanto imagens construídas por cada ser não está preenchida apenas pelo que é "percebido, sentido e representado", mas concomitante à carga sentimental, pois quando um ser constrói uma representação, tal construção é preenchida subjetivamente com suas "recordações, significados e experiências" (KOZEL, 2007, p. 117). O mapa mental consiste num texto que precisa ser lido, logo interpretado e, para tanto, foi utilizada a "Metodologia Kozel" para a análise e concepção desse modo de representação, pois:

$\mathrm{Na}$ metodologia Kozel $(2008,2009)$ de decodificação dos mapas mentais é preciso observar a forma de representação dos elementos (ícones, letras, linhas, etc.), distribuição dos elementos na imagem (de forma isolada, horizontalmente, de forma dispersa, etc.), especificidade dos ícones (elementos naturais, construídos, móveis, humanos) e outros aspectos ou particularidades (GOMES; VARGAS, 2011, p. 7).

No primeiro momento, os elementos analisados consistiram na "forma de representação dos elementos na imagem", em como as "formas de representação" aparecem no mapa mental, como formas geométricas, linhas, letras entre outras (KOZEL, 2007, p.133). No segundo momento, foi interpretado como os "elementos" estavam dispostos. Nessa perspectiva, o estudante teve liberdade para organizar o desenho na folha de sulfite A4, que não tinha margem. Também foi observada a disposição dos detalhes dos desenhos, se estavam na horizontal, dispersos, ou em perspectiva. A análise posterior se remeteu "à especificidade dos ícones", quanto à representação dos elementos de paisagem "natural", "construída", "móveis" e "humanos". 


\section{Perspectivas do meio ambiente representadas nos mapas mentais dos estudantes}

Consciência maior arma Mapa pra qualquer lugar (Céu)

Os mapas são representações produzidas pelos seres humanos e constam de um processo de codificação do que o ser conhece, imagina e está em sua consciência. Com isso, a epígrafe denota essa discussão, pois a "consciência maior arma" demonstra onde acontece o processo de codificação e decodificação. Os elementos do real são passíveis de codificação a partir da consciência, assim como o processo de decodificação, aprimorando a cognição. "Mapa para qualquer lugar", a consciência está no ser e o ser está em um lugar construindo sua consciência a respeito, elaborando mapa, representação, pois:

Simultaneamente através dos cincos sentidos e da mente, as pessoas percebem o espaço a sua volta e interagem com ele (tornam-se conscientes dele). A percepção se desenvolve como resposta desses sentidos aos estímulos externos e fornece à pessoa conhecimentos imediatos a respeito do que a cerca (TUAN, 1980). A apreensão sensível, imediata de mundo, refere-se ao sentido, mas para que este se torne um significado ou conceito é preciso à reincidência de uma série de experiências regulares e retroativas (LIMA, 2007) (MALANSKI; KOZEL, 2015, p. 156; grifo da pesquisadora).

O conhecimento imediato acerca do espaço corresponde ao processo cognitivo do ser, e correspondem também aos conhecimentos prévios, que embora não sejam expressos em uma perspectiva científica denotam o "significado" e o "conceito" para cada desses alunos. A forma como o ser se relaciona com o espaço influencia na percepção que tem do próprio.

Há discussões acerca das representações e uma dessas consiste na cartografia de forma sistemática e geométrica (RICHTER, 2011), porém, numa concepção humanista, a cartografia tem embasamento na vivência do cotidiano, para além das convenções oficiais, porque:

[...], conforme Seemann, é uma cartografia subversiva, contramapeamento ou, ainda, mapa não convencional, pois se baseia em concepções pessoais do espaço e comumente funde a linguagem cartográfica com a expressão artística (MALANSKI; KOZEL, 2015, p.160). 
Almeida e Passini (2002) defendem a perspectiva cartográfica e a importância do processo de codificação para ter mais êxito no momento de decodificar. Neste trabalho, utilizou-se o mapa mental como meio cartográfico por consistir num entendimento acerca da representação de Geografia e Meio Ambiente pelos estudantes, sendo que, dessa forma, a pesquisadora subjetivamente pensou em perceber o espaço do estudante, entendendo-se que:

Mapear é de uma ou outra maneira tomar a medida do mundo, porém mais do que meramente toma-la, figurando a medida tomada em tal maneira que possa ser comunicada entre pessoas, lugares e tempos. A mediação do mapeamento não é restrita ao matemático, ela é igualmente pode ser espiritual, política ou moral. Pelo mesmo sinal, o registro do mapeamento não é confinado ao que é para arquivar, mas também inclui o que é lembrado, imaginado, contemplado. O mundo figurado através do mapeamento assim pode ser material ou imaterial, existente ou desejado, inteiro ou em partes, experimentado, lembrado ou projetado em várias maneiras (COSGROVE, 1999 apud KOZEL, 2007, p.116).

As subjetividades vêm da consciência, do processo cognitivo do estudante, em como absorve as informações, codifica-as e, como fica em sua mente, todo entendimento pode se tornar mapas. Os mapas mentais contrapõem a discussão inteiramente geométrica das representações espaciais. Assim, conforme apontado na citação anterior, os sentidos sinestésicos são múltiplos para projetar o que se deseja "arquivar", mas também o que é "lembrado", "imaginado", "contemplado", além das vivências, por meio do cotidiano no espaço. Esse entendimento aponta que "[...] a construção mental de uma imagem é proveniente da cognição associada à bagagem cultural (experiências, valores, informações etc)" (KOZEL, 2007, p.120-121).

Acerca das representações mentais, Kozel aduz que:

As representações provenientes das imagens mentais não existem dissociadas do processo de leitura que se faz do mundo. E nesse aspecto os mapas mentais são considerados uma representação do mundo real visto através do olhar particular de um ser humano, passando pelo aporte cognitivo, pela visão de mundo e intencionalidades. A imagem de algo reflete uma construção simbólica (2007, p.121).

No contexto desta pesquisa, observou-se que o entorno dos estudantes influencia os mapas mentais, uma vez que esses foram analisados a partir da realidade espacial de cada aluno, sendo que alguns são bem enfáticos ao demonstrar o espaço do discente, diferenciando do estudante de outra escola. 
Isso se explica pelo fato dos signos serem construções sociais (KOZEL, 2007, p. 115), pois "os mapas mentais revelam a ideia que as pessoas têm do mundo e assim vai além da percepção individual refletindo uma construção social" (KOZEL, 2007, p.117). Com isto, os mapas mentais têm origem em três contextos espaciais e relações ambientais e isso foi perceptível nos trabalhados apresentados. "[...], os diferentes tipos de espaços refletem a forma como o homem se relaciona com o seu meio, e permitem inferir que o meio constitui-se elemento importante a ser considerado no que tange aos aspectos relacionados às representações gráficas" (KOZEL, 2007, p.120). Além disso, os grupos de mapas mentais com signos refletem as construções sociais absorvidas da vivência e interação dos seus espaços vividos.

$\mathrm{Na}$ perspectiva de Meio Ambiente, os elementos do mapa mental A (Figura 2) contém o grupo de mapas mentais provenientes da $\mathrm{El}$, que expõem ícones em perspectiva e apenas naturais, como árvores, vegetação rasteira, céu, nuvens, pássaros e um tamanduá, pois está se alimentando em um formigueiro. Para o estudante (10 anos, $6^{\circ}$ ano) a localização de onde mora fica "ali atrás da Escolinha", e isso demonstra como utiliza a escola como ponto de referência para explicar onde ele reside. Ele justifica o que conhece do próprio espaço "a minha mãe mora a todo a minha família mora aqui e Eu gosto de Estudar" e, com isso, apontou que o que conhece sobre o seu espaço está relacionado às pessoas que também vivem nele, que têm um vínculo com ele. Houve uso de lápis de cor para desenhar e pintar e o desenho remete à percepção a respeito do meio ambiente, sem apresentar interação humana, não tendo nenhum elemento humano, móvel ou construído.

Semelhante ao mapa anterior, o B (Figura 2) está em perspectiva e apresenta aspectos naturais, como árvores, pássaros, céu e sol. O estudante (10 anos, $6^{\circ}$ ano) escreveu "arvore e paisagem" como o que conhece do seu espaço e isso corrobora com o desenho e quem sabe com a ideia que veio à sua mente no momento em que deveria desenhar sobre meio ambiente, além de ser uma realidade da aldeia, que possui muita vegetação e animais.

Outra estudante (12 anos, $7^{\circ}$ ano) retratou em C (Figura 2) uma cena do seu cotidiano em relação ao lixo, por meio de ícones e letras, apresentado na horizontal com elementos naturais (grama) e humanos (duas pessoas). Há uma frase explicativa no desenho que diz "Esse é um desenho de uma mãe e uma filho a mãe varrendo e a filha cantando os lixos do quintal", apontando que a estudante considerou importante contextualizar o desenho com a explicação, mas não se colocou na situação, pois está se referindo em terceira pessoa. Em sua narrativa aponta: "Eu gosto da aldeia porque aqui não é como na cidade aqui nós somos praticamente livre, na cidade agente não podemos sair se divertir e outras coisas, minha brincadeira favorita e esconde-esconde, [...]". Isso demonstra a sua visão a respeito do espaço da aldeia com relação ao da cidade, pois ela considera que nesse espaço há mais liberdade. 
A

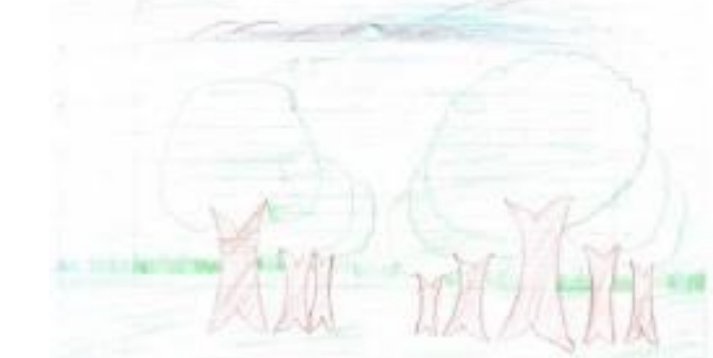

C
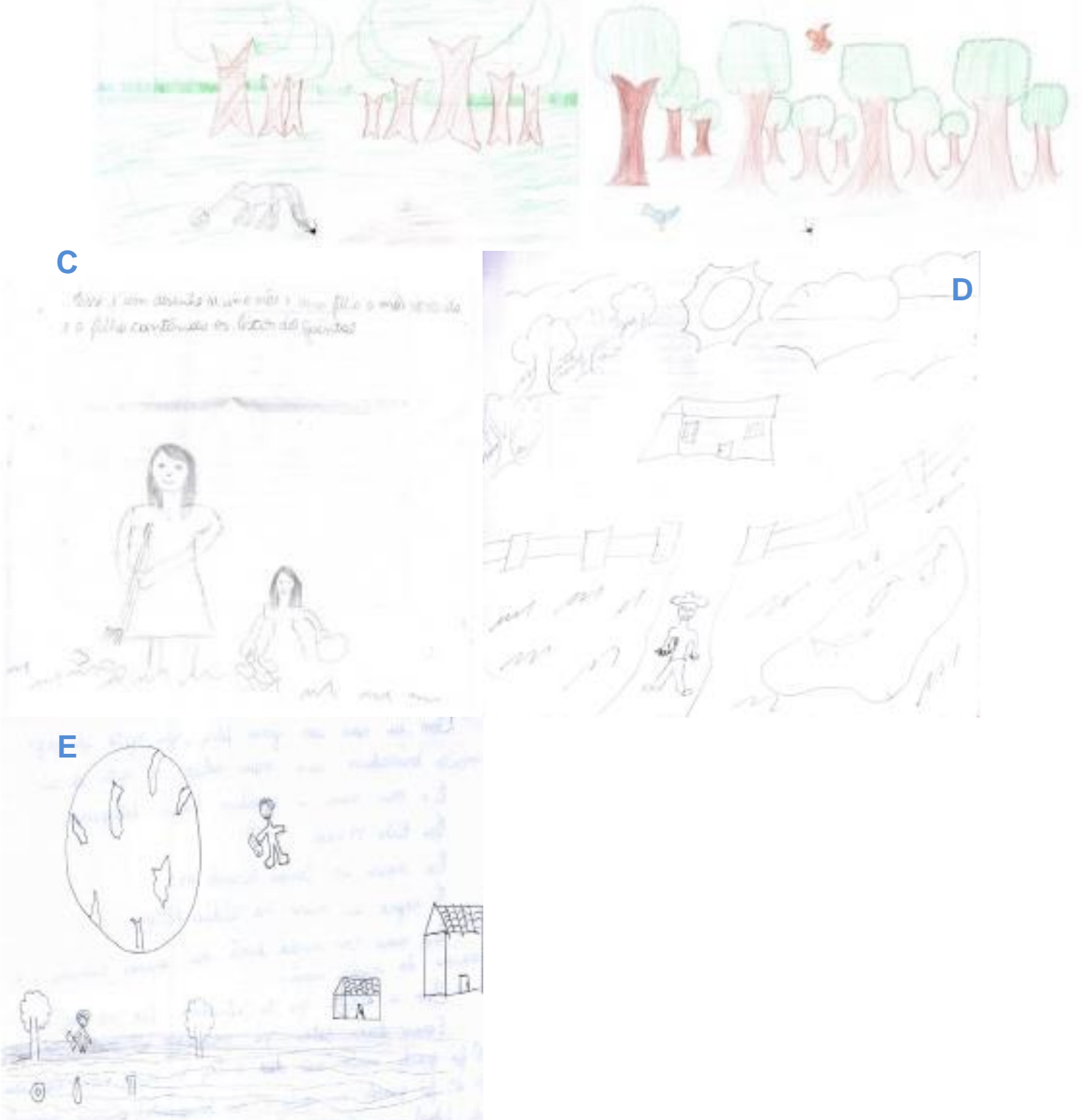

Figura 2: Mapas mentais de Meio Ambiente, elaborados por alunos da Escola Indígena.

No mapa mental D (Figura 2), o estudante representou um misto de ícones em perspectiva, com elementos construídos (casa e cerca), naturais (lagoa, peixes, grama, árvores, nuvens, pássaros e sol) e humanos (uma pessoa). Aspectos mais particulares podem ser observados nesse trabalho, pois, ao pensar o meio ambiente, o contextualizou com a interação do homem 
na sua percepção, diferente dos mapas mentais A e B desse mesmo grupo, identificando o homem como um elemento humano no desenho com um aspecto de uma interação saudável com a natureza.

$\mathrm{O}$ desenho $\mathrm{E}$ (Figura 2) tem ícones e formas geométricas com uma sobreposição dos planos em relação ao planeta desenhado. Uma parte do desenho está distribuído em perspectiva e a outra dispersa, pois as casas, planeta e uma pessoa não estão sobre uma superfície. Em desenhos, há duas maneiras de representar uma casa e o que foi desenhado nessa oportunidade mostra "uma casa tradicional, de linhas mais ou menos geométricas, estilo habitat totalmente codificado: casa de telhado pontudo [...]" (MĖREDIEU, 1974, p. 52). Há também elementos naturais (árvores e planeta), construídos (casas e lixos) e humanos (duas pessoas). O estudante (14 anos, 9ano) representou o lixo, que é uma problemática das aldeias, por não haver coleta, o que faz com ele esteja presente por toda parte. Esse estudante mora na Aldeia Ypegue, vizinha da Lagoinha, e contextualiza sobre o seu espaço, alegando que "Bom o espaço onde eu moro é calmo é tranquilo e eu gosto de viver lá", relacionando as experiências cotidianas de vivência nesse espaço.

Assim, dois desenhos apresentam uma ideia de natureza intacta, enquanto mostram certa interação saudável, sendo que outros refletem a questão do lixo. Os aspectos particulares demonstram diferentes mensagens e ideias acerta do meio ambiente.

O mapa mental A (Figura 3 ) do estudante ( $9^{\circ}$ ano) carrega um misto de informações e cores, é um desenho bem feito, e mostra aspectos do real e não, vindos da imaginação, o que pode ser entendido um pouco pelo fato de 0 estudante se intitular como um "gamer". O desenho possui ícones, linhas e formas geométricas em perspectiva. Há elementos naturais e construídos e o que conhece o estudante conhece sobre o seu espaço são "poucas coisas conheço sobre onde moro, mas eu sei que nem todo mundo e bem de vida aqui". Ele faz um apontamento que, do pouco que sabe, compreende que as pessoas não têm o mesmo padrão de vida, e isso consiste numa observação muito interessante, pois é uma temática discutida na Geografia e pode ser pensada de diversos pontos de vista. Uma das mensagens que o desenho traz está em torno da presença do lixo, que pode se remeter a uma observação do meio ambiente.

$\mathrm{Na}$ lateral do desenho B (Figura 3), o estudante (15 anos, 9o ano) explicou que "O que se entende por Geografia? É o estudo, que estuda esse tipo de matéria estuda a vida Sabe melhor É sempre Bom, saber um pouco mais Afinal. Ninguém sabe de tudo". Assim, para ele, estudar a vida consiste na percepção do estudante enquanto objeto da Geografia. O mapa mental está organizado em um retângulo e possui ícones, letras, linhas e formas geométricas na horizontal e há elementos naturais (árvores, rio e Sol), construídos (rua e lixo) e móveis (carros). O desenho remete à emissão de gases pelos carros, além da presença de lixo no rio e numa interpretação pessoal parece ter representado a questão de queimadas na vegetação, o que ocorre no cerrado em tempo de estiagem. É interessante ressaltar como pensa Revbea, São Paulo, V. 12, № 2: 355-373, 2017. 
a localização da escola em relação à sua casa, "A escola esta localizada 100 metro à esquerda da minha casa". Sobre o seu espaço escreveu: "Bom é uma sociedade burocrática se você não seguir ela totalmente é excluído". Essa sociedade burocrática pode ter uma conotação, ao estudante, de um conjunto de questões a serem seguidas pelas pessoas, conforme a construção social, e a ignorar pode consequentemente ocasionar exclusão.

A representação C (Figura 3) está dispersa, com ícones, letras, linhas e formas geométricas. Nuvens e uma "árvore" são os elementos naturais; os construídos consistem na "estrada", "bandeira do Brasil" e na "uzina", como o estudante (15 anos, 9 ano) apontou no desenho. Os ícones são autoexplicativos, com uma seta e uma legenda para cada, e dispersos. A ideia que se tem é que o estudante elencou tais características para retratar o seu espaço, além dos elementos representativos de cada aspecto da sua percepção espacial e um exemplo disso é a bandeira como um significado da jurisdição a que esse espaço remete. Ele sabe que o seu espaço "é grande", mostrando que o entendimento do espaço que conhece aponta para uma questão de tamanho.

A representação D (Figura 3 ) trata de situações econômicas que interligam o campo e a cidade e se mostra de forma dispersa, mas em perspectiva também, com ícones, letras, linhas e formas geométricas. Há elementos naturais (árvores, animais e corpo d'água), construídos (rua, casa, fábrica, cerca), móvel (caminhão) e humano (pessoa). O estudante (15 anos, 9ำ ano) expôs detalhes no desenho, demonstrando a interação com o meio ambiente a partir de atividades de produção de matéria prima no campo e o transporte dessa para a "Fabrica para preparar", além de outras atividades, como uma pessoa laçando um animal. Toda a perspectiva do desenho pode ser explicada pelo fato do estudante ter tido uma vivência em fazenda, pode retratar o contexto de onde ele morou, com atividade que teve contato enquanto viveu nesse lugar, mostrando que ele tem em mente a interação dos dois espaços. Em sua narrativa, ele explica que "moro na cidade agora mais antes morava na fazenda moro com meus avós por que meus pais istão para fazenda". Escreveu também: "eu conheço muitas coisas conheço meu limite e hora de fala e hora de fica quieto, eu gosto de joga futebol, [...] adoro ir pra fazenda e vou todo final de semana [...]", alardeando que o seu espaço está relacionado aos limites relacionais.

Foram perceptíveis, no desenho E (Figura 3), ícones e linhas em perspectiva, apenas com elementos naturais (árvore, grama, pássaros, corpo d'água, peixes e sol). Esses elementos demonstram a percepção de meio ambiente, representando céu, terra e água interligados, sem interação humana. O estudante (16 anos, $9^{\circ}$ ano) escreveu "meu espaço é de escola pra casa e de vez em quando para a casa dos amigos [...]", ou seja, seu sentido de espaço consiste no movimento da sua espacialidade, de onde perpassa indo de casa para a escola e vice versa.

Os desenhos desse grupo remetem a problemas como o lixo, gases poluentes e incêndio, mas foram detalhistas também em abordar a relação

revista brasileira educação ambiental 
entre a cidade e o campo, assim como retratar uma ideia de natureza intacta. Dois desenhos apontam a presença de indústrias e usinas, que também emitem gases, contribuindo para a perspectiva de degradação do meio ambiente. Há signos nos detalhes dos desenhos, nos quais se percebem o quanto as vivências do estudante nos espaços onde viveu e vive influem em suas percepções, não só de meio ambiente, mas também de Geografia.
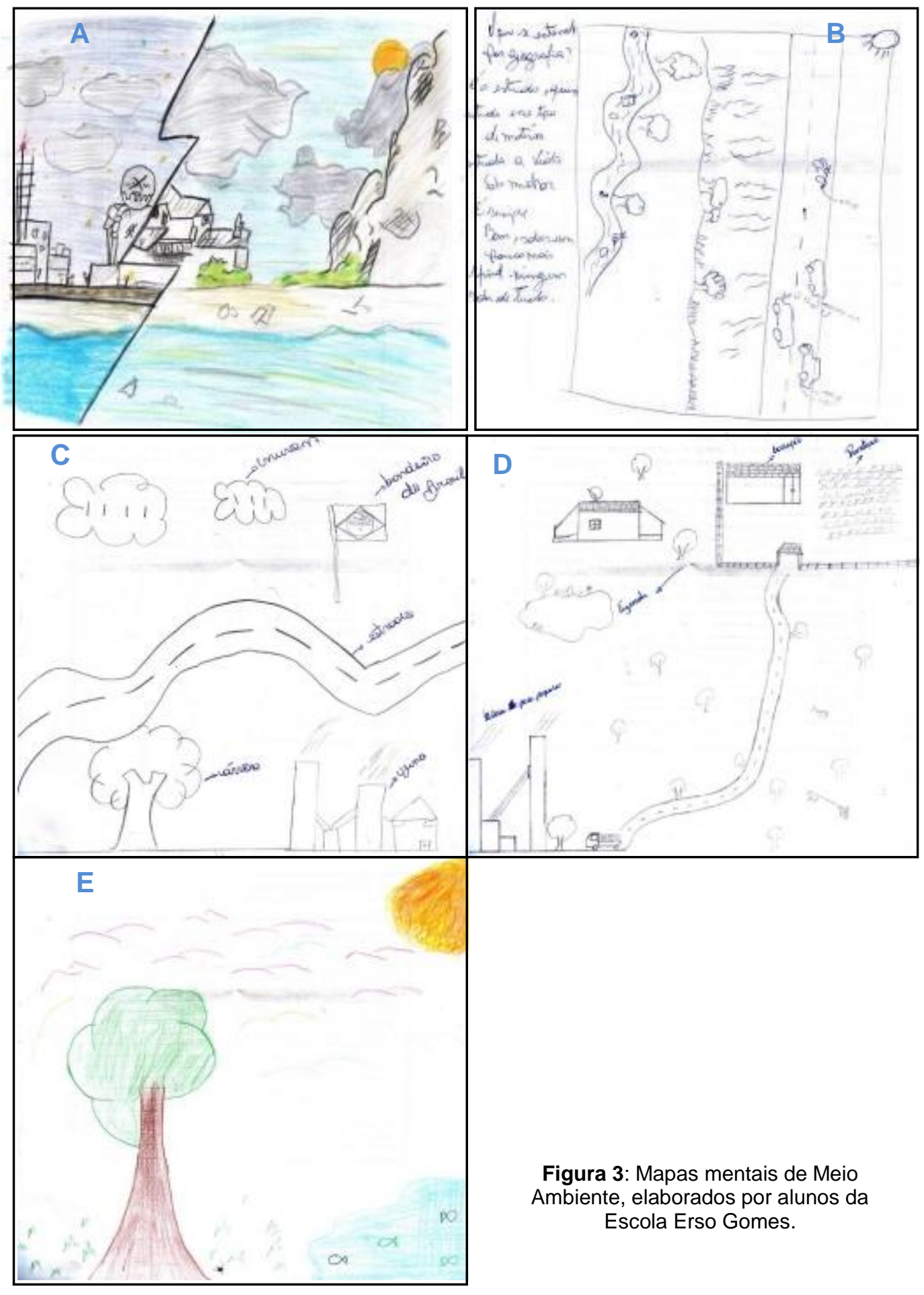

Figura 3: Mapas mentais de Meio Ambiente, elaborados por alunos da Escola Erso Gomes. 
$\mathrm{Na}$ perspectiva de Meio Ambiente, no grupo de mapas mentais provenientes da EP, para a estudante (17 anos, $7^{\circ}$ ano), a ideia de meio ambiente foi representado no desenho A (Figura 4), a partir de ícones, linhas e formas geométricas, em perspectiva e dispersos. Os elementos naturais (árvores) e construídos (casas) conotam que as casas e árvores representam a interferência humana na natureza, compondo o meio ambiente na percepção da estudante, com a apresentação de cores.

O mapa mental B (Figura 4) traz ícones, letras, linhas e formas geométricas, todos dispersos em perspectiva, com elementos naturais (árvores e animais), construídos (estrada), móveis (ônibus) e humanos (pessoa). A estudante (12 anos, $6^{\circ}$ ano) demonstra como percebe a interação com os animais e a atividade de pecuária como relações ambientais nesse cotidiano. $O$ ônibus é algo bem presente para suas idas à escola, além de ser algo com o qual convive bastante onde mora, percebendo-o no seu caminho de ida e volta da escola. A respeito do seu espaço, escreveu que "Eu gosto do meu quarto Por que tem televisão, Eu gosto da Escola Por que me detraiu com as atividades", apontando o que lhe promove afetividade, tanto no seu espaço em casa, como na escola.

O estudante (16 anos, 9o ano), que mora na cidade, mas estuda na escola pantaneira, desenhou C (Figura 4) por meio de ícones e linhas em perspectiva com elementos naturais (animais, plantas e árvores). Seu desenho demonstra uma percepção de uma natureza sem interferência humana, mas com outros animais, mostrando que essa pode ser a percepção que o estudante tem ao pensar a temática ambiental. Para ele, o espaço tem relação com o "Que eu posso fazer o que eu quiser.", determinando uma ideia de domínio de suas ações acerca de uma delimitação, além de, quem sabe, conotar liberdade.

A concepção de espaço da estudante (14 anos, 9a ano) que escreveu que "eu sei sobre o meu espaço. Que ele é muito legal posso andar pra onde quiser nos campos andar a cavalo de trator", mostra que as atividades citadas conotam o espaço onde ela vive e como é a sua vivência nesse meio ambiente. O desenho D (Figura 4) aduz ícones, linhas e formas geométricas em perspectiva e horizontal, com elementos naturais (árvores, relevo, chuva, nuvens e pássaros), construídos (casa e fábrica) e móveis (carro). O mapa mental apresenta várias atividades, como a chuva no alto dos morros e as fumaças saindo das indústrias, mostrando a percepção da estudante para o meio ambiente. Alega essa aluna que "A minha escola esta localizada na Fazenda Taboco acho que uns 45 quilômetros da cidade de Aquidauana, Eu amo a minha escola tem professores legais ótimos profissionais". Além do seu apreço pela escola e professores, percebe-se interessante a forma como localiza a escola, tratando da quilometragem distante de Aquidauana como sendo a referência, o que pode ser explicado pelo fato da estudante morar na mesma localização.

Os mapas mentais (Figura 4) são preenchidos com percepções do próprio espaço dos estudantes e esses detalhes são perceptíveis, com

revista brasileira educação ambiental 
exceção de $C$, que demonstra uma visão de uma natureza sem interferência humana. Este conjunto de percepções constrói ideias ambientais para outros espaços além do que convivem, como a cidade também.

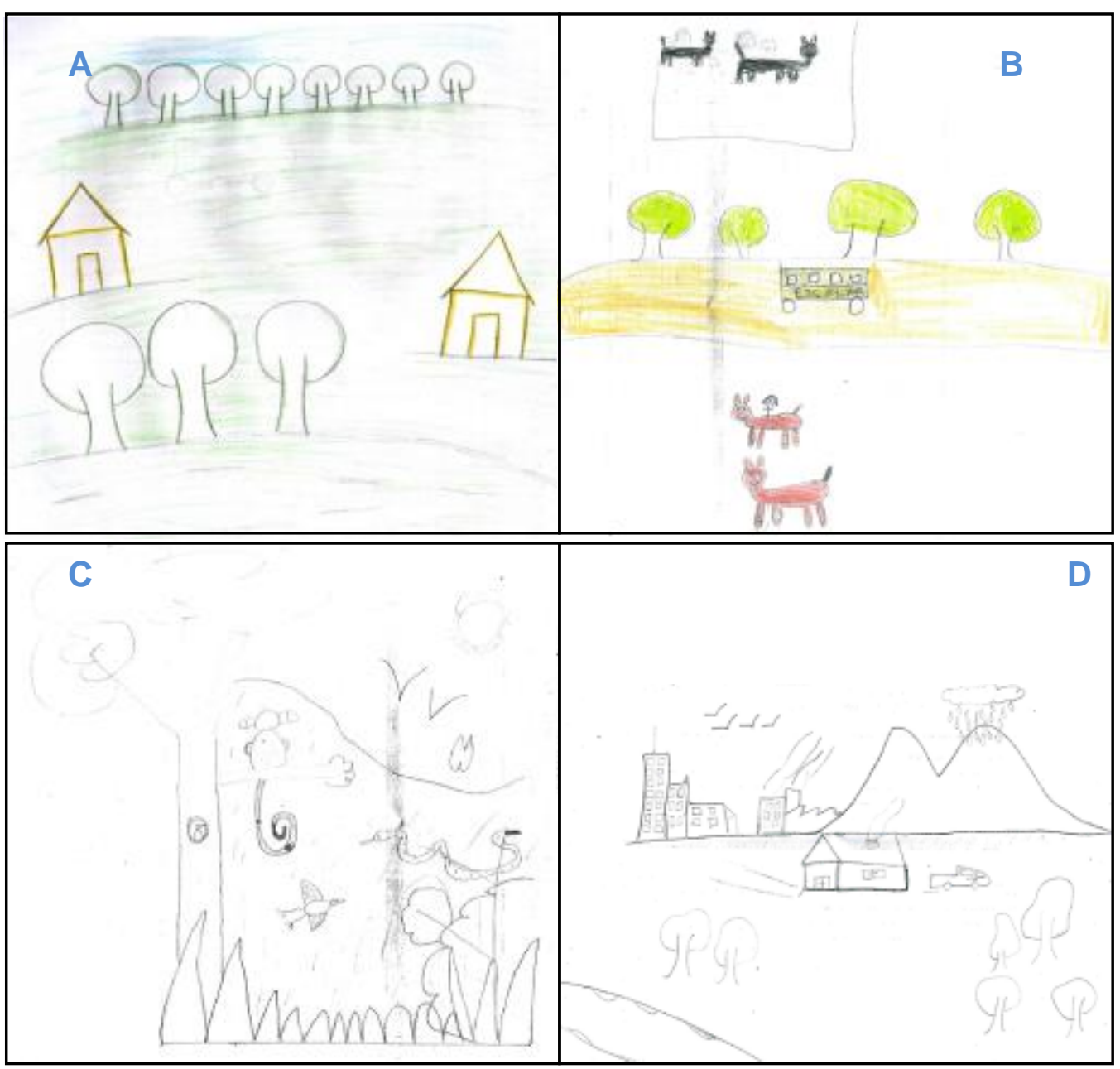

Figura 4: Mapas mentais de Meio Ambiente, elaborados por alunos da Escola Pantaneira.

Ao interpretar cada mapa mental de todos os grupos pensando a Geografia e Meio Ambiente, o que o grupo corresponde pode se relacionar à decodificação de mensagens que os estudantes codificaram, mas a análise pode carregar as percepções próprias da pesquisadora, do que ela entende desses dois focos e como os percebeu em cada desenho. Sobre isto Mèredieu raciocina que:

Os diferentes elementos de uma mesma cena são encarados sob diferentes ângulos [...]. Para considerar um objeto de determinado ponto de vista, não é necessariamente estar consciente dele. Em compensação, "representar-se ou representar graficamente o mesmo objeto em perspectiva, supõe que se tem consciência, simultaneamente, do ponto de vista sob o qual é percebido e das transformações devidas à

Revbea, São Paulo, V. 12, № 2: 355-373, 2017. 
intervenção desse ponto de vista" (MÈREDIEU, 1974, p. 55$57)$.

Percebe-se, com isso, que outra pessoa poderia destacar outras percepções, além disso, os grupos de mapas mentais foram organizados por escolas, devendo se considerar que, no geral, os estudantes vivem no mesmo contexto espacial3, mas que, mesmo assim, ao representarem conotam diferentes visões acerta do espaço, de Geografia e meio ambiente, com detalhes refinados da sua percepção, tendo em vista as experiências cotidianas no espaço e também experiências vividas no passado, no mesmo ou em outro espaço, que trazem uma carga para compreender e perceber o espaço atual. $O$ real foi codificado nos desenhos a partir de aspectos particulares, pois "O espaço começa por ser espaço-agido, vivido. A representação propriamente dita do espaço só começa com a figuração e com a preocupação de imitar o real' (MĖREDIEU, 1974, p.45).

Os desenhos e apontamentos nas narrativas demonstram o que a criança gosta e desgosta nesses contextos, e "[...] ao lado desses desenhos ditados à criança pelo meio ambiente, encontramos representações mais espontâneas que revelam seus gostos [...]" (MÈREDIEU, 1974, p.52).

A interação do ser com o espaço constrói a sua percepção geral. Assim, todas as subjetividades nesse material podem significar o que o estudante percebeu e como imagina acerca do seu espaço e isso foi percebido e discutido na análise de cada mapa mental, uma vez que são:

Dotados de informações perceptivas, sensações e imaginações espaciais, as pessoas são capazes de representar a partir de imagens mentais o espaço percebido ou imaginado. Para tanto, representação, conforme Merleau-Ponty (1999), se configura como uma função simbólica e objetivante dada pela consciência a partir da interação entre a pessoa e o espaço. Assim, ela é responsável por dar significado a algo percebido, representando fenômenos naturais e sociais, para a compreensão de acontecimentos ditos sobrenaturais e, principalmente, para perpetuar a consciência humana de mundo (MALANSKI; KOZEL, 2015, p.158).

Os grupos de mapas mentais apresentados acima abordando o Tema Transversal Meio Ambiente no cotidiano dos estudantes, revelaram para a El que houve três perspectivas ao desenhar, como a natureza sem interação humana, com interação sustentável e a interação problemática com impactos,

\footnotetext{
${ }^{3}$ Havendo exceções, pois há estudantes que estudam na EC e moram em assentamentos, assim como estudantes da EI que moram em outras aldeias e/ou chácaras próxima a aldeia que a escola está localizada.
} 
como a questão do lixo. Na EC, os mapas mentais demonstraram a problemática do lixo, com ênfase à emissão de gases por carros e indústrias, incêndios na vegetação, e também abordaram a relação entre a cidade e o campo. A abordagem dos gases poluentes nos mapas mentais pode ser explicada por esses estudantes viverem na cidade, onde a emissão de gases por tais atividades se concentra e se torna mais significativa. $\mathrm{Na} \mathrm{EP}$, verificamse percepções de uma natureza sem interação humana, além de outra perspectiva pensando as problemáticas ambientais não só no campo, mas também da cidade, fazendo uma relação entre ambos os espaços.

\section{Considerações finais}

Os mapas mentais e as narrativas construíram um material profícuo para o entendimento das percepções espaciais e ambientais dos estudantes, a análise dos desenhos por escola e temática demonstrou o que tem mais significância de uma escola para outra. As atividades práticas nas EI e EP construíram um diálogo com a concepção teórica do trabalho, no qual os estudantes foram protagonistas das atividades e a apresentação de fotografias e anotações dos estudantes expôs o entendimento para com seu espaço, tendo em vista a questão ambiental.

A alfabetização geográfica e a EA ocorrem por meio do repensar. As atividades da pesquisa de campo levaram a pensar isso, pois os estudantes desenharam o seu "chão", que comprovou que as "leituras de mundo" existem, os conhecimentos prévios brotam da vivência de cada ser, e isso pode ser ressaltado para ter mais significância.

Em síntese, as leituras, práticas e reflexões da coexistência desta pesquisa promoveram à pesquisadora o desenrolar de algumas indagações que em alguns momentos parecem ter resposta e em outros não. $O$ aprendizado levou ao redescobrir-se e assim a refletir a Geografia com certa flexibilidade, por meio das poesias de Manoel de Barros, uma Geografia de significância, de coexistência, e, sobretudo de luta a favor de uma educação pública de qualidade, em todos os níveis e modalidades, em cada chão do município de Aquidauana. As coexistências e reflexões continuam...

\section{Referências}

ALMEIDA, R.D.; PASSINI, E.Y. O espaço geográfico: ensino e representação. 12 ed. São Paulo: Contexto, 2002.

BARROS, M.W.L.. Poesia completa. São Paulo: Leya, 2010. Disponível em:< http://goo.gl/MUTBi2 > Acesso em: 17 set. 2014.

BRASIL. Lei no 9.795, de 27 de Abril de 1999. Dispõe sobre a educação ambiental, isntitui a Política Nacional de Educação Ambiental e dá outras providencias. Diário Oficial [da] República Federativa do Brasil, Brasília, 28 de abril de 1999. 
BRASIL. Secretaria de Educação Fundamental. Parâmetros curriculares nacionais: meio ambiente. Disponível em: < http://goo.gl/v7Yzpw > Acesso em: 04 de fev. de 2014.

FREIRE, P. A importância do ato de ler: em três artigos que se completam. 47 ed. São Paulo: Cortez, 2006.

GOMES, A.H.A.S; VARGAS, M.A.M. Mapas mentais como representação do espaço vivido e percebido. In: Coloquio Internacional: Educação e Contemporaneidade". 4., 2011, São Cristovão. Anais... São Cristovão, 2011.

GONZALEZ, S. Educação ambiental autopoiética com as práticas do bairro ilha das caieiras entre os manguezais e as escolas. 2013. Tese (Doutorado em Educação) - Universidade Federal do Espírito Santo, Centro de Educação.

KOZEL, S. Mapas Mentais - Uma forma de linguagem: perspectivas metodológicas. In: KOZEL, S; SILVA, J.C; GIL FILHO, S.F. Da percepção e cognição a representação: reconstruções teóricas da Geografia Cultural e Humanista. São Paulo: Terceira Margem. p.114-137.

LACOSTE, Y. A Geografia: Isso serve, em primeiro lugar, para fazer a guerra. Tradução de Maria Cecília França. Campinas: Papirus, 1988.

MALANSKI, L.M; KOZEL, S. Representação do espaço escolar a partir de mapeamento coletivo: uma abordagem da Geografia humanista. Ateliê Geográfico, Goiânia, v.9, n.2, p.154-169, ago/2015.

MARQUES, C.N; SOUZA, C.C. Memória Terena: história e língua, educação escolar e cultura, identidade e resistência. Disponível em: $<$ http://goo.gl/ffkdwg $>$. Acesso em 21 jul. 2015.

MARTINS, É.R. Geografia e ontologia: o fundamento geográfico do ser. GEOUSP - Espaço e Tempo, São Paulo, № 21, p. 33-51, 2007.

MEDINA, N.M; SANTOS, E.C. Educação Ambiental: Uma metodologia participativa de formação. 3. ed. Petrópolis: Editora Vozes, 2003.

MÈREDIEU, F. O desenho infantil. Tradução de Álvaro Lorencini e Sandra M. Nitrini. São Paulo: Cultrix, 1974. 82p. Tradução de: Le Dessin D’Efant.

RESENDE, M.S. A Geografia do aluno trabalhador: caminho para uma prática de ensino. São Paulo: Edições Loyola, 1986.

RICHTER, D. O mapa mental no ensino de Geografia: concepções e propostas para o trabalho docente. São Paulo: Cultura Acadêmica, 2011.

SATO, M.; CARVALHO, I.C.M. Itinerários da educação ambiental: um convite a percorrê-los. In: SATO, M.; CARVALHO, I.C. (Orgs.). Educação ambiental: pesquisas e desafios. Porto Alegre: Artmed, 2005. p. 11-15.

SEGURA, D.S.B. Educação ambiental na escola pública: da curiosidade ingênua à consciência crítica. São Paulo: Annablume, 2001. 